\title{
PEDRO SAINZ RODRÍGUEZ: UN DIPUTADO MONÁRQUICO Y CATÓLICO EN LAS CORTES DE LA SEGUNDA REPÚBLICA
}

POR

\author{
JULIO ESCRIBANO HERNÁNDEZ
}

\section{RESUMEN}

Reseña de la actuación política del diputado por Santander, Pedro Sainz Rodríguez en las costes de la segunda República, incidiendo en su papel de aglutinador del sector derechista durante la legislatura.

\begin{abstract}
Review of the political performance of the congressman by Santander, Pedro Sainz Rodriguez in the costs of the second Republic, studing especially his agglutinant paper of the right during the legislature.
\end{abstract}

\section{El asambleísta en el Parlamento republicano}

Como hombre de Renovación Española, Sainz Rodríguez se definía católico en lo religioso, monárquico en lo político, constitucional en lo jurídico y demócrata en lo social. A comienzos de 1933 había perfilado su comportamiento con estas pautas, que orientaban su actividad parlamentaria desde que fuera elegido diputado por Santander en las elecciones del 28 de junio de 1931. Con el sacerdote Lauro Fernández y González, que defendía la causa social en la región cántabra, representaba a la minoría santanderina en aquellas Cortes que se abrieron el día 14 de julio muy a tono con el nuevo ambiente republicano.

Don Lauro era veintiún años mayor que él, había nacido en un pueblo de la provincia de Santander, en Queveda, había sido nombrado Rector del Semina-

Actas del I Congreso de Historia de la Iglesia y el Mundo Hispánico

Hispania Sacra, 52 (2000) 
rio de Corbán en 1916 y estaba muy vinculado con los Sindicatos Agrícolas Montañeses. Uno y otro habían recibido sinceras felicitaciones de los miembros de la Acción Regional Independiente, en la que estaban alistados mauristas, liberales, jaimistas e integristas y habían aceptado los agasajos de los amigos de Potes que les obsequiaron con un banquete en la fiesta de Santo Toribio de Liébana tres días después de la apertura de las Cortes, es decir, el 17 de julio de 1931. Pero no sólo recibieron el reconocimiento localista y provincial, sino también la gratitud del partido Acción Nacional que había reunido en el Hotel Palace de Madrid a cuantos habían conseguido un escaño y compartían ideales en oposición al régimen republicano.

Presidiendo las Cortes del 14 de julio encontró Sainz Rodríguez a su antiguo profesor de Ética de la Universidad Central, Julián Besteiro, que estaba sorprendido por la falta de orden en aquellas primeras sesiones ${ }^{1}$. Veía don Julián que algunos españoles no estaban preparados para los cambios rápidos y confundían la democracia con el desorden, la vulgaridad y la chabacanería y que otros se apuntaban al cambio radical buscando mejorar su fortuna, sin importarles ser cancerberos del espíritu revolucionario después de haber cobrado su paga como confidentes de Martínez Anido.

Ante estas carencias y defectos de la vida política era normal que toda persona que tuviera presente la grandeza de España dijera que realmente el pueblo español no estaba representado en el Parlamento. Para Sainz Rodríguez no sintonizaban con la cultura occidental aquellos que confundían los cambios políticos con el incendio de los edificios religiosos ${ }^{2}$ o pretendían olvidar el pasado. Como intelectual y como político no podía interpretar la cultura europea sin tener en cuenta la religión cristiana y así consideraba anacrónico aceptar unos principios laicos que herían la conciencia de un pueblo que había desarrollado su cultura religiosa. Por todo esto estuvo atento al anteproyecto de Constitución que fue entregado el día 6 de julio, después de dos meses de elaboración, y también al proyecto que se terminó el 18 de agosto con 121 artículos y una disposición transitoria para que fuera discutido en las Cortes.

Una vez presentado por Luis Jiménez de Asúa, tomaron la palabra veinte oradores que, con sus intervenciones a favor y en contra a la totalidad del

\footnotetext{
1 El día 30 de julio de 1931 enviaba una nota a cada diputado con este texto que conserva Sainz Rodriguez en su Epistolario: «Al no ser conocidos por los ujieres todos los sefiores Diputados, algunos entran en el Salón de Sesiones y hasta toman asiento en los escafios. Son personas ajenas a la Cámara. Por lo cual se ha de acreditar la calidad de Diputado exhibiendo el carnet de ferrocarriles o la tarjeta de identidad facilitada por el oficial mayor.”

2 Casi un centenar de edificios religiosos fueron incendiados y saqueados entre los días 11 y 13 de mayo de 1931 en Madrid, Alicante, Valencia, Murcia, Sevilla, Málaga y Cádiz.
} 
mismo, prolongaron el debate hasta el día 9 de septiembre. La comunicación de Sainz Rodríguez, que pretendía aconsejar en un turno «a favor» para que la República fuera viable, fue el día 8 de septiembre y, si embargo, estuvo acompañada de incidentes poco agradables. Casi dos tercios de los que estaban presentes en la Cámara, la abandonaron nada más anunciarse su turno de palabra y no lo hicieron pacificamente sino dando gritos y utilizando la palabra «asambleista» como insulto al flamante diputado. Oreja Elósegui que conoció a Largo Caballero ejerciendo de Consejero de Estado en la Dictadura de Primo de Rivera les increpó: «¿Qué opinará el Sr. Largo Caballero de este espectáculo?», pero pocos se dieron cuenta del alcance de la pregunta y entre protestas y rumores respondieron: «QQué tiene que ver el Sr. Largo Caballero con esto?» Realmente no querían entender que en la Dictadura de Primo de Rivera tenía más responsabilidad un Consejero de Estado que un asambleísta.

Sainz Rodriguez se sintio satisfecho con la propaganda que se hizo de su intervención con este acontecimiento y con la selección de los diputados que le escucharon entre los que estaban Cambó, Unamuno, Ortega y Gasset, Melquíades Álvarez, Santiago Alba, Sánchez Guerra, Largo Caballero... Algunos republicanos pensaban como Anastasio Moreno que le escribió unos días después, desde Teruel, una carta fechada el 11 de septiembre de 1931 con el siguiente texto: «Respetable seffor: Conste que no somos correligionarios, que nos separa un abismo; soy republicano convencido desde que naci y en el republicanismo milito; ahora bien, no es el republicanismo modernista de estos republicanos que gritan en defensa de la libertad y son más tiranos que la tiranfa que combaten. Por lo sucedido a usted protesto y hágole presente mi más viva simpatía...»

Con la autoestima muy alta inició su discurso pensando que algunos estaban por accidente en el hemiciclo y pocas enseñanzas podian dar los que se encontraban tan faltos de civismo y de humanidad. Comenzó su exposición hablando sobre el texto constitucional con cierta independencia para que la Cámara, mayoritariamente de izquierdas, conociera la opinión de los seguidores de la derecha, que tenían una representación tan pequeña que se habían quedado sin voz y casi sin audiencia, pero tenían que convivir con la nueva Constitución. Dijo que ésta se había redactado sin pensar en la realidad de España y que encontraba en ella graves defectos. Sabía Sainz Rodríguez que para elaborarla se habían tenido muy en cuenta en el proyecto un buen número de Constituciones modernas, que demostraba la preparación intelectual de los 21 miembros que formaban la comisión parlamentaria presidida por Jiménez de Asúa ${ }^{3}$. Se

${ }^{3}$ La Comisión estaba formada de este modo: presidente, Luis Jiménez de Asúa; vicepresidente, Emilio Iglesias; secretario, Fernando Valera; vicesecretario, Alfonso García Valdecasas; vocales: Ricardo Samper, Clara Campoamor, Justo Villanueva, Mariano Ruiz-Funes, Luis Araquistain, Trifón Gomez, 
habían traducido, copiado y estudiado la Constitución alemana de Weimar, la de Austria, la de Checoslovaquia, la de Uruguay y la de Méjico. Esta última había influido en el problema religioso que tuvo muy presente Sainz Rodríguez en su intervención.

Articuló su análisis en tres bloques: contenido, estructura política y espíritu religioso de la Constitución. Nada más iniciar su discurso manifestó que el contenido del proyecto constitucional era propuesto como la solución para todos los problemas del pueblo español, que la Carta Magna que naciera del mismo era la salvación y la felicidad y así con el nombre de Constitución se comenzaban a bautizar calles, monumentos y hasta personas. Criticó este mesianismo constitucional haciendo entender que no se renovaría en profundidad la vida española si no contara con la colaboración y el cambio de los seres humanos con independencia de su tendencia política. La Constitución era para él un cauce por el que discurriría la tarea común y la vida del pueblo español y no una encrucijada de caminos intransitables para dividir en bandos a la sociedad. Realmente el contenido de sus artículos estaba recargado de normas ajenas a la temática constitucional, más propias de un reglamento interno de partido político que de una Carta Magna, según el criterio de Sainz Rodríguez. Consideraba un grave error haber introducido en la Constitución los temas revolucionarios para protegerlos de la lucha dialéctica, haberse olvidado del pluralismo cultural y haber despreciado a la mayoría sociológica de los católicos. Para los partidarios de la derecha y para los seguidores de la izquierda debería ser la Constitución un estatuto de garantías que permitiera el libre desarrollo de la vida de los partidos dentro de la legalidad. Pero, si se introducían en ella el tema del divor$\mathrm{cio}^{4}$, las normas para la disolución de las Órdenes Religiosas ${ }^{5}$ y las leyes contra las garantías de la propiedad se hería a una gran mayoría de los españoles que podían volverse en contra de una Constitución a la que consideraban sectaria.

Jerónimo Bugeda, Enrique de Francisco, Leopoldo Alas, Juan Botella Asensi, Antonio Rodríguez Pérez, Gabriel Alomar Villalonga, Antonio Xirau Palau, Bernardino Valle Gracia, Jesús María Leizaola Juan Castrillo Santos y José María Gil Robles.

${ }^{4}$ El 13 de junio de 1931 Miguel de Unamuno publicaba en El Sol un artículo sobre el divorcio en el que decía que al pueblo le preocupaba poco este asunto. Para los católicos el matrimonio era un sacramento indisoluble porque hacía presente la unión de Cristo y la Iglesia y para el Estado era un contrato meramente civil. Así, cuando se trataba en los anteproyectos constitucionales el tema, se estaba obedeciendo ua una especie de sentimiento anticanónico, 0 , si se quiere, anticlerical».

${ }^{3}$ Siguiendo el laicismo del siglo XIX se incluyó en la Constitución la disolución de las Órdenes religiosas. Cuando el Nuncio Tedeschini visitó a Azafía el 18 de noviembre pidiéndole que no se marcharan los religiosos ni se cerraran sus colegios, le contestó que pensaba aplicar lealmente la Constitución para garantizar la seguridad del Estado, y esto se lo decía sin haber sido aprobada. Años después reconoceria que se había jugado el porvenir de la República con la Ley de Congregaciones religiosas, con el artículo 26 de la Constitución, con la neutralidad de la escuela y con la política laica.

Actas del I Congreso de Historia de la Iglesia y el Mundo Hispánico Hispania Sacra, 52 (2000) 
Sainz Rodríguez que veía en ella un buen instrumento para perseguir a los cató$\operatorname{licos}^{6}$ decía que debía despojarse de su anti-religiosidad, de su sectarismo y de su anticlericalismo abriendo amplios campos de convivencia para todos los españoles. Así sería estatuto de legalidad respetado por cualquier grupo.

La estructura política de la Constitución la fundaba en el poder del Parlamento y del Presidente, emanado de la voluntad del pueblo español. Por esto, los miembros del Parlamento como servidores de una comunidad humana pluralista, que había depositado su confianza en sus instituciones, debían asumir los conflictos, encauzarlos, resolverlos y no arrojarlos a la calle para que los ciudadanos les dieran solución.

Por último, analizaba la ausencia de espíritu religioso en la Constitución y decía que ningún Estado podría mantenerse y ser fuerte si marginaba la conciencia religiosa. ¿Dónde fundamentaría la justicia, la paz, la convivencia, la libertad y todos los valores que trascienden el presente? ¿Qué sentido hallaría en la actividad diaria? ¿Podrían evolucionar sus leyes si se aniquilara la fuerza espiritual y no existiera un horizonte de justicia? Para un pueblo católico eran un lastre las ideas antirreligiosas y no podía pretender su unión una Constitución que las defendiera. Según su pensamiento un Estado anticlerical, antieclesiástico y antirreligioso sería anacrónico y estaría marginado, porque nacería desnacionalizado en España, donde el quehacer histórico ha tenido su presencia religiosa ${ }^{7}$. El nacionalismo español estaba abierto a una idea universal, a una vivencia católica. Por esto, proponía que se debería elaborar una Constitución en la que estuviera la conciencia nacional por encima de los intereses de los partidos y respetara las hondas raíces de la tradición fundada en la cultura religiosa. Hizo notar la antinomia que existía entre la apología de la cultura religiosa, que hizo en su discurso Fernando de los Ríos, y el apoyo simultáneo a una Constitución que perseguía el hecho religioso.

En esta intervención del día 8 de septiembre, tres meses antes de la promulgación de la Constitución, queda clara su toma de postura ante el problema religioso que sería discutido en el análisis de cada artículo. También queda patente la oposición de quienes veían en Sainz Rodriguez el signo de la alianza entre la Iglesia y la Monarquía.

\footnotetext{
6 En la sesión del dia 8 de octubre de 1931 declaro Gil Robles: «Entendemos que el proyecto constitucional es un proyecto de persecución religiosa; por consiguiente, en estas condiciones no podemos aceptarlo.3

7 El catalán Carrasco Fomiguera, de Unión Democrática de Cataluña, llegó a decir: «Los republjcanos católicos nos sentimos engafados por no haber respetado la República nuestros sentimientos y faltado a sus promesas" (cf. Francisco MarTi GLABERT, Política religiosa de la Segunda República Española, Pamplona, Eunsa, 1998, p. 84).
} 


\section{DeFENSA DE LA Iglesia: EL DEBATE DEL ARTículo $26^{8}$}

Una gran mayoría pensaba que la cuestión religiosa era un problema capital y que existía un especial interés en legislar dentro de la Constitución la separación de la Iglesia y el Estado, el laicismo docente, la disolución de las Órdenes religiosas, el matrimonio civil, el divorcio, la secularización de los cementerios $^{9}$. Con tal legislación quedaba muy claro que se pretendía arrancar de raíz el sentimiento religioso de los españoles. José María Gil Robles, que perteneció por el grupo agrario a la comisión de los 21 parlamentarios que prepararon el proyecto con Luis Jiménez de Asúa, declaró cuando se propuso la aprobación del artículo 26 que ya habían llegado al límite de un acuerdo posible entre las derechas y las izquierdas y se declaró contrario al proyecto de Constitución si se aprobaba dicho texto y que abrirían un nuevo período constituyente ${ }^{10}$.

\footnotetext{
${ }^{8}$ Este artículo, después de aprobado, quedo redactado así en la Constitución de 1931: «Todas las confesiones religiosas serán consideradas como asociaciones sometidas a una ley especial. El Estado, las regiones, las provincias y los municipios no mantendrán, favorecerán ni auxiliarán económicamente a las iglesias, asociaciones e instituciones religiosas. Una ley especial regulará la total extinción, en un plazo máximo de dos antos, del presupuesto del clero. Quedan disueltas aquellas órdenes religiosas que estatutariamente imponen, además de los tres votos canónicos, otro especial de obediencia a autoridad distinta de la legitima del Estado. Sus bienes serán nacionalizados y afectados a fines benéficos y docentes. Las demás órdenes religiosas se someterán a una ley especial votada por las Cortes constituyentes y ajustadas a las siguientes bases: $1 .^{2}$ Disolución de las que, por sus actividades, constituyen un peligro para la seguridad del Estado. 2." Inscripción de las que deban subsistir en un Registro especial dependiente del Ministerio de Justicia. 3. Incapacidad de adquirir y conservar, por sí o por persona interpuesta, más bienes de los que, previa justificación, se destinen a su vivienda o al cumplimiento directo de sus fines privativos. 4. Prohibición de ejercer la industria, el comercio o la enseñanza. 5. Sumisión a todas las leyes tributarias del país. $6{ }^{\circ}$ Oblización de rendir anualmente cuentas al Estado de la inversión de sus bienes en relación con los fines de la asociación. Los bienes de las órdenes religiosas podrán ser nacionalizados.»

9 José María GıL RoBles en su obra No fue posible la paz (Barcelona, Ed. Ariel, 1968, pp. 53-54) dice estas palabras: «La aprobación del articulo 26 de la ley fundamental no sólo fue una notoria injusticia, sino que constituyó un gravísimo error de consecuencias incalculables (...) El problema religioso se convirtió desde ese momento en bandera de combate, agudizando hasta el paroxismo el choque de las dos Españas... En esa sesión de las Cortes Constituyentes se sembró el germen de la discordia, que acabaría por enfrentar a los hermanos con las armas en la mano.n

${ }^{10}$ En la obra citada No fue posible la paz, p. 54, dice: "Y mientras la minoría agraria luchaba en los escaños, en cumplimiento de su deber, volvía a reunirse la comisión, clandestinamente y sin citar a los dos representantes derechistas, para acordar la redacción definitiva del artículo 26, en el cual el sectarismo de la Cámara centraba sus ataques en la Compañía de Jesús. Por verdadera casualidad pude enterarme de lo que sucedia. En unos instantes, con prisa febril, comenzaron a redactarse las enmiendas. Diecinueve conseguimos entregar en la Mesa antes de que reglamentariamente se nos lo impidiera. Por más que el resultado estuviera previsto, había, al menos, que defender el terreno palmo a palmo.

Las izquierdas furiosas por nuestra actitud, acordaron que la sesión fuera permanente. Con un ligerísimo descanso, duró desde las cuatro y media de la tarde del día 13 de octubre hasta las ocho menos
}

Actas del 1 Congreso de Historia de la Iglesia y el Mundo Hispánico Hispania Sacra, $52(2000)$ 
Sin embargo, la aprobación del artículo fue acogida con aplausos y vivas a la República aquel 15 de octubre de 1931 y cuando la minoría vasco-navarra contestó con vivas a la libertad se produjo confusión y se inició la dialéctica de los puños ${ }^{11}$. Fue aprobado por 175 votos a favor y 59 en contra, estando ausentes 223 diputados y tres ministros. Las minorías vasco-navarra y agraria se retiraron de la Cámara después de votar en contra y el presidente Niceto Alcalá Zamora y Miguel Maura, que era Ministro de Gobernación, abandonaron el Gobierno $^{12}$. Como este Gobierno era provisional, sus poderes volvieron al Parlamento con la dimisión de Alcalá Zamora y Maura, encontrando en Azaña a la persona preparada para aceptar la presidencia.

Sainz Rodríguez también abandonaba el Parlamento y el día 3 de noviembre de 1931 se justificaba así ante sus electores santanderinos: «Y ahora, señores, yo os diré que nosotros, los católicos, nos hemos retirado con la convicción de la inutilidad de nuestro esfuerzo, porque sabíamos, además, que aquella Cámara sectaria hacía de las ideas nuestras ludibrio irrespetuoso». Estaba convencido de que se podía hacer políticamente muy poco dentro del sistema y comenzó a visitar a militares, como el general Orgaz, para conspirar y crear un gran partido de derechas. Con frecuencia se preguntaba cómo existiendo una mayoría de católicos en la nación eran minoría en el Parlamento y con estas premisas deducía la falta de unión entre la nación y las Cortes.

Por todo esto, trabajó para que el día 15 de diciembre de 1931 estuviera en la calle el primer número de la revista Acción Española que defendía la monarquía y despertaba la conciencia católica en España, protestó contra la Ley de Congregaciones Religiosas y propugnó la acción armada contra los enemigos de la lglesia: «Hoy ruedan lágrimas, pero no brillan las espadas». En sus páginas defendió

veinte de la mañana del dia 14. ¡Horas inolvidables las de aquella noche tristisima! A las invectivas e insultos que salían de los escarios se sumaba el tumulto de las tribunas, repletas de gentes especialmente reclutadas.y

11 No era raro este comportamiento. Sainz Rodríguez respondió a una bofetada de Pérez Madrigal con un puntapié y un pufietazo, según refiere el Diario $A B C$ (Madrid, 23 de julio de 1932) y una carta que le envía Francisco Franco, General de la 15 Brigada de Infanteria, ese mismo día desde Coruf́a.

12 El Cardenal Vidal y Barraquer y el nuncio Tedeschini llegaron a un acuerdo, el 14 de septiembre, con el presidente N. Alcalá Zamora y el ministro de Justicia Fernando de los Ríos para prescindir de radicalismos y establecer una situación juridica de la Iglesia mediante un convenio, modus vivendi o un concordato. Para este fin, el nuncio y los obispos se inclinaban a hacer algunas concesiones para garantizar, según se comunicó al secretario de Estado Eugenio Pacelli, «la personalidad juridica de la Iglesia el respeto a las congregaciones religiosas y a sus bienes, la subsistencia del presupuesto del clero y la libertad de ensefianzas. Este acuerdo y sus garantías desaparecieron con el artículo 26 y el presidente de la República entendió que debía dimitir al ser aprobado.

E. Comín Colomer califica de absurda esta dimisión, porque deja su puesto cuando se aprueba el artículo 26 de la Constitución y acepta firmar después el código político de los esparioles. (Cf. Historia secreta de la Segunda República, Vol. I, Madrid, 1954, p. 166). 
Sainz Rodríguez una monarquía hereditaria, católica, orgánica, antiparlamentaria, con mando único rechazando la monarquía liberal a la que se calificaba de «República coronada» por haber hipotecado su poder a los partidos políticos, al sufragio universal y al discurso del parlamento. Era la respuesta a los excesos demagógicos del proyecto de Constitución debatido anteriormente ${ }^{\mathrm{t} 3}$.

Las ideas que defendía Acción Española se basaban en un catolicismo militante y en una monarquía corporativa, totalitaria y tradicional. Sainz Rodríguez decía que los españoles nunca habían sentido la ciudadanía del partido político sino de la tradición que había puesto a prueba y desarrollado sus mejores valores. Como diputado aceptaba la responsabilidad de servir a la nación antes que al partido político, pensaba más en los intereses nacionales que en los intereses sociales que distribuían los escaños del Parlamento, en el nuevo estado más que en los regionalismos separatistas, a los que consideraba signos claros de la decadencia española. La tradición catalana y la vasca, por ser católicas, se entremezclaban con la tradición nacional espafiola donde encontraban su sentido histórico, donde se integraban los regionalismos y donde se respetaban las peculiaridades por un Estado que haría posible la libertad dentro de la unidad de la Patria. Tenía muy claro que no se podía ser nacionalista de nación alguna sin ser a la vez tradicionalista.

Lo regional y lo nacional debían unirse en sus tradiciones históricas aceptando las diferencias como elementos que hacen posible su engranaje. Cuando no eran aceptados los hechos diferenciales, se destruían las tradiciones, se aniquilaba la cultura común y se desconocían los motivos de la convivencia historica, cualquier región quedaba entregada a los caprichos de las minorías separatistas. Para mantener la unidad nacional en la diversidad y en el pluralismo regional proponía el mando único, que paradójicamente no se tuvo en cuenta durante la monarquía parlamentaria y liberal, en la que el Rey ni reinaba ni gobernaba mediatizado por los partidos políticos.

Encontraba en la Monarquía unos valores que no se daban en la Revolución. El monarca se identificaba más con el pueblo y se entregaba sin lucha, si tenía que derramar sangre para mantenerse en el poder; no sucedía así con los gobiernos dependientes del triunfo de los partidos, que se defendían y estaban dispuestos a hacer la guerra antes de ceder su puesto a otro sistema político. Su propia experiencia política le confirmaba estas ideas.

${ }^{13}$ El historiador Raymond Carr resume los acontecimientos de este modo: «No fueron el radicalismo democrático ni el idealismo social de la Constitución, sino las cláusulas religiosas, englobadas en el artículo 26, las que enfurecieron a la oposición, dividieron al gobierno y crearon la posibilidad de una unión de la derecha para defender a una Iglesia perseguida.» «El New Deal republicano», España 1808-1939, Ariel, Barcelona, 1969, p. 580.

Actas del I Congreso de Historia de la Iglesia y el Mundo Hispánico Hispania Sacra, 52 (2000) 
A partir de enero de 1932 intensificaba su abierta colaboración con Acción Nacional, con la Agrupación Regional Independiente, con Acción Española, con Renovación Española, con la Derecha Regional Valenciana, con Comunión Tradicionalista y con otros grupos de derechas que podrían formar el gran bloque nacional. Varias veces admitió que las derechas no podían colaborar con la República porque ésta no las aceptaba.

\section{TRES TEMAS DE REBELDIA}

\section{El voto femenino}

Al discutirse el 11 de septiembre de 1931 el Título III del Proyecto de Constitución ${ }^{14}$ en el que se concedía el voto a la mujer, la diputada Victoria Kent y los socialistas se opusieron porque consideraban que estaba condicionado por la Iglesia. Sainz Rodríguez en las conferencias que daba a grupos de mujeres les hacía ver que su voto valía tanto que su opinión iba a ser decisiva en la política espaftola. Es más, les decía que participaban de una gloriosa tradición en la que las mujeres intervinieron en el gobierno del Estado con gran provecho e indudable gloria para España. Pensaba que la política se había reforzado con la colaboración femenina. En relación con la polémica del voto exponía que nunca se pudo atacar la concesión con razones doctrinales sino guiados por los intereses del partido y cuando oyó, como supremo argumento, que no debía concederse el voto a la mujer porque no estaba preparada para ello, se formuló rápidamente la pregunta: ¿Y acaso está preparado este señor para ser diputado? No entendía que se hablara de igualdad y se atacara la concesión del voto femenino. Así salía al paso de los prejuicios que despertaba en la mujer su intervención en la vida pública, diciendo que se debía acabar con ellos y tendrían ellas que salir de la casa para dar la batalla a los que iban contra ese hogar y contra la formación de los hijos.

\section{Confrontación con el Estado anticatólico}

Si a los pocos días de aprobada la Constitución Sainz Rodríguez mantenía cierta esperanza en el régimen y pedía que las derechas no le atacaran, en la primera semana de enero declaraba: «Hoy el Estado es nuestro enemigo y lo que

14 En el articulo 23 del Proyecto, en su segundo apartado, se proponía lo siguiente: «Se reconoce, en principio, la igualdad de derechos de los dos sexos.» 
ha hecho es organizarse para perseguirnos» ${ }^{15}$. Se atrevió a decir que el recuerdo de la gloriosa tradición de España debía llevar a los españoles a una postura agresiva contra el Estado, al que deberían asaltar, si fuera preciso, por crear unas leyes que destruían la familia, la propiedad y el sentido de la vida.

Consideraba que se había producido la decadencia española por la completa separación entre Espafia y su Estado, ya que éste se había impuesto a la nación con un programa de partido y una falta de respeto a sus valores espirituales. Como diputado sabia que representaba a una derecha incompatible con el proceso de desnacionalización que se estaba realizando.

Se oponía al socialismo al que consideraba como la tiranía de los mediocres, incapaces de crear riquezas teniendo que limitarse a distribuir las que otros consiguieron con preparación, orden y trabajo. Según su valoración la doctrina socialista que se imponía en las Cortes limitaba la capacidad de los más activos, de los más emprendedores y de los más inteligentes; destruía unas veces la responsabilidad, otras el sentimiento individual y, por fin, aniquilaba el nacionalismo en la política internacional ${ }^{16}$. $Y$ cuando estos valores desaparecían, los pueblos, las regiones y hasta las clases sociales pedían privilegios y prebendas para si mismas sin tener en cuenta las necesidades nacionales. Con estas imágenes, acompañadas del ataque político, se procuraba Sainz Rodríguez cierta animadversión de los radicales socialistas ${ }^{17}$.

La agresión al Estado quedó significada en los hechos del 10 de agosto de 1932. Sainz Rodríguez conocía bien el plan de Sanjurjo con el que había colaborado y cuya sublevación siguió desde Biarritz animando a los monárquicos en la casa de la familia Ansaldo. Ante el fracaso defendió con poca eficacia a los que fueron deportados en aquel mes de agosto, pues en la Navidad de ese año son varios los que pasan sus días en Villa Cisneros o en penales apartados de familiares y amigos. Tanto en estos lugares como en el Aaiún y en las Canarias se creaba una reacción en contra del Gobierno y a favor de quienes llegaban allí sin ostentación ni recursos.

${ }^{15}$ Cf. «EI diputado a Cortes don Pedro Sainz Rodríguez recomienda la unión de las derechas españolas con un solo ideario y un solo programan, El Diario Montañés, Santander, 7 de enero de 1932.

16 Razonaba estos datos diciendo que el socialismo esperaba igualar a todos los seres humanos, pero como no está en manos de nadie hacer que los inferiores sean superiores, resulta que las revoluciones socialistas lo único que lograban era que los superiores se pusieran al nivel de los inferiores.

17 Podemos tener en cuenta su enfrentamiento con el diputado socialista Joaquín Pérez-Madrigal, narrado en el diario $A B C$ (Madrid, 23 de julio de 1932) y reproducido en Julio EsCRIBANO HERNÁNDEZ, Pedro Sainz Rodriguez, de la Monarquia a la República, FUE, Madrid, 1988, pp. 192-193.

Actas del I Congreso de Historia de la Iglesia y el Mundo Hispánico

Hispania Sacra, 52 (2000) 
Aglutinando a los conservadores contra un gobierno anticatólico y sectario

El sábado 21 de enero de 1933 se acordó en la casa madrileña de Antonio Goicoechea la formación de un nuevo partido, que se fundaría el 23 de febrero de ese año con el nombre de Renovación Española. Tenía su sede en el $\mathrm{n}^{\circ} 4$ de la calle Villanueva, donde Sainz Rodríguez trataba con varios diputados monárquicos que poco a poco se fueron inscribiendo para fortalecer el partido: Ramón de Carranza, Ramiro de Maeztu, El Conde de Vallellano, Alfredo Serrano Jover, José Calvo Sotelo, José Sabucedo, Andrés Amado...

Realmente pretendía que la derecha no estuviera marginada en la actividad social y convocaba reuniones donde fuera necesario, unas veces en Madrid con diputados afines y otras en la provincia de Santander con los campesinos e industriales del partido de Reinosa y de Torrelavega, que simpatizaban menos con su programa político, logrando favorables estados de opinión. En varias ocasiones recorrió la provincia de Santander, por la que salió diputado en todas las legislaturas de la República, para mantener el valor y la actividad de las derechas. Pero, más de una vez, fracasó, como le sucedió en Reinosa ${ }^{18}$, multiplicando el miedo y la cobardía de los pequeños grupos atacados por las juventudes socialistas.

Los resultados finales en aquellos municipios santanderinos, a los que se aplicó en aquellas elecciones de abril de 1933 la calificación de «burgos podridos" dada por Azaña, fueron satisfactorios: los concejales de la derecha pasaron en la comarca de 100 a 233. A pesar de este éxito político, Sainz Rodríguez fue acusado a finales de mayo de 1933 de no intervenir en el Parlamento, de asistir poco al Congreso, de tener escasa relación con la provincia espaciando demasiado las visitas, de no ser un conductor dinámico de su política y de mantener silencio ante las cartas que le dirigían ${ }^{19}$. Y es posible que esto sucediera porque siempre valoró más su actividad intelectual que la parafernalia política.

\section{CONCLUSIONES}

Desde Renovación Española pretendía Sainz Rodríguez agrupar a la derecha, revisar la Constitución y derogar las leyes anticatólicas sobre todo cuando se dio cuenta que la República habia iniciado su quiebra en marzo de 1933. En

\footnotetext{
${ }^{18}$ Sobre los sucesos del 31 de marzo de 1933 en el Hotel Universal de esta ciudad existe abundante documentación, tanto en el Archivo de Sainz Rodriguez como en la prensa de la época. Puede consultarse Julio EsCRIBANO HERNANDEZ, op. cit., pp. 207-212.

19 Carta de Emilio López Bisbal, Archivo de PSR (Epistolario), Santander, 22 de mayo de 1933.
} 
otros ambientes ese mismo año se fue gestando Falange Española, que nacería en la campaña de las elecciones del 19 de noviembre con el apoyo económico de Renovación y añadiría al grupo parlamentario los nombres de José Antonio y del Marqués de Eliseda.

La nueva Cámara que se formó el 3 de diciembre de 1933 era consciente de que los electores pedían una política de derechas. Lerroux se propuso dialogar con católicos y monárquicos para hacerles ver que la República no era incompatible con la Iglesia ni con el derecho a la propiedad. Consecuentemente no se aplicó la Ley de Congregaciones firmada el 2 de junio, se paralizó la reforma agraria, bajaron los salarios agrícolas, se devolvió a las Órdenes religiosas las propiedades confiscadas y se aumentó el número de efectivos de la Guardia Civil.

Con la presencia de Calvo Sotelo, que llegó a Madrid el 2 de mayo de 1934 en virtud de la ley de amnistía aprobada el 21 de abril anterior, se estructuró el Bloque Nacional que le eligió como su presidente. En el Bloque Sainz Rodríguez representaba a Renovación Española y Victor Pradera a los tradicionalistas. Se buscaba, no siempre acertadamente, una política inteligente basada en la justicia social y en la autoridad capaz de unificar voluntades para romper con la agitación revolucionaria. El Bloque Nacional pretendía la conquista del Estado.

La República estaba dispuesta a mostrar su fuerza con la declaración de la huelga general en España, la revolución en Cataluña y en Asturias para rechazar la creciente presencia de la derecha en las Cortes y en el Gobierno donde ocupaba la cartera de los ministerios de Justicia, de Trabajo, de Agricultura y de Obras Públicas. Sainz Rodríguez calificaba la revolución de octubre del 34 como el suicidio de la República, pues «un régimen democrático que en su constitución no reconocía más fuente de poder que la soberanía popular, no podia, por desconfianza o por puritanismos doctrinales, oponerse a que la gran masa de los diputados, que llegaron al Parlamento en las primeras Cortes ordinarias, participase en el Poder ${ }^{20}$. No estuvo de acuerdo con la huelga general, ni con el estado de guerra, ni con las intrigas posteriores, pero era consciente de que el sectarismo habia eliminado a la República y la colocaba ante un Bloque Nacional que había redactado su manifiesto el 8 de diciembre de 1934 calificado de fascista y prohibido por la censura.

Criticaba a la institución republicana y a su gobierno no sólo por ser contraria a su posición monárquica, sino por haber desaprovechado su momento histórico para evitar la revolución violenta. Tenía claro que las revoluciones no nacen del hambre, de un estado de miseria ni de la postración del pueblo, pues

\footnotetext{
20 Pedro Sainz Rodríguez, Testimonio y Recuerdos, Barcelona, Ed. Planeta, 1978, p. 155.
} 
habia comprobado que los obreros de Asturias eran los más ricos y mejor pagados de España, sino de la prosperidad de ciertos elementos sociales, a quienes la revolución les proporcionaba medios para intentar el salto violento al poder y para romper la jerarquía establecida.

Buscó un estado integrador que acabara con la división y dispersión que producía la lucha de clases, pero no defendía el estado fascista sino la justicia, la libertad y el trabajo; un estado que fuera árbitro de la contienda social y creara conciencia en los patronos, técnicos y obreros de que estaban al servicio de un interés nacional supremo, que jerarquizaba los intereses parciales de clase. Este Estado Nuevo, que se anunciaba en cada una de sus intervenciones, le exigió retirarse del Parlamento tras la muerte de su amigo Calvo Sotelo por incompatibilidad con la República y dedicarse a conspirar abiertamente contra ella. 